\title{
HXI open A qualitative interview study: patient accounts of medication use in early rheumatoid arthritis from symptom onset to early postdiagnosis
}

\author{
Anne Townsend, ${ }^{1,2}$ Catherine L Backman, ${ }^{1,2}$ Paul Adam, ${ }^{3}$ Linda C Li ${ }^{2,4}$
}

To cite: Townsend $A$, Backman CL, Adam P, et al. A qualitative interview study: patient accounts of medication use in early rheumatoid arthritis from symptom onset to early postdiagnosis. BMJ Open 2013;3:e002164.

doi:10.1136/bmjopen-2012002164

- Prepublication history and additional material for this paper are available online. To view these files please visit the journal online (http://dx.doi.org/10.1136/ bmjopen-2012-002164).

Received 27 September 2012 Revised 22 December 2012 Accepted 10 January 2013

This final article is available for use under the terms of the Creative Commons Attribution Non-Commercial 2.0 Licence; see http://bmjopen.bmj.com

For numbered affiliations see end of article.

\section{Correspondence to} Dr Anne Townsend; atownsen@exchange.ubc.ca

\section{ABSTRACT}

Objective: To examine accounts of medication use in participants with early rheumatoid arthritis (RA) from symptom onset to early postdiagnosis.

Design: Qualitative study with in-depth, personal interviews.

Participants: 37 women and one man, aged 30-70s, with a diagnosis of RA $<12$ months.

Main outcome measure: Participants' experiences and feelings of medication use in early RA.

Setting: British Columbia, Canada.

Results: Medications were central to how people managed symptoms and disease. Two main themes were identified, showing that optimum medication use was hampered, and how this related to delayed diagnosis and effective care. The first theme, 'paradox of prediagnosis reliance on over the counter (OTC) medications', describes how people's self-management with OTC medications was 'effective'. Participants relied extensively on OTC medications for pain relief and to maintain 'normal life'. However, as this contributed to delayed medical consultation, diagnosis and effective treatment, OTC medication was also potentially detrimental to disease outcome. The second theme, 'ambivalence around prescription medications post diagnosis', describes how adherence was hindered by patient beliefs, priorities and ambivalence towards medications.

Conclusions: This study highlights how people use medications in early RA and contributes to a better understanding of medication use that may transfer to other conditions. Given the drive towards active selfmanagement in healthcare and patients' ambivalence about using strong medications, an in-depth understanding of how these combined factors impact patient experiences will help healthcare providers to support effective medication practices. The reported extensive reliance on OTC medications may speak to a care gap needing further investigation in the context of health behaviours and outcomes of patient selfmanagement.

\section{INTRODUCTION}

Medications paradoxically promise both relief and burden for people with chronic

\section{ARTICLE SUMMARY}

Article focus

- To understand the experiences of medication use in people with early rheumatoid arthritis from symptom onset to early postdiagnosis.

Key messages

- Our study suggests an over-reliance and extensive use of over the counter (OTC) medications detrimental to health.

- People continued to self-medicate in place of a general practitioner consultation when symptoms were severe and debilitating but masked by high and regular doses of OTC medications.

- Ambivalence about medication use suggests that we need to understand patient priorities and experiences better in order to support adherence.

Strengths and limitations of this study

- This is an in-depth analysis of a relatively large qualitative dataset, offering insight into our participants' experiences of medication use. However, given the nature of qualitative research, we do not claim generalisation to other populations. Experiences may be transferable to other settings with individuals who have similar characteristics.

illness. In rheumatoid arthritis (RA), medications ease symptoms and can limit disease progression, but often complex regimens can exacerbate adverse reactions and side effects. ${ }^{1}$ These combined factors can promote tensions and ambivalence around medication use and foster non-adherence detrimental to individuals and healthcare systems: 'Non-adherence is important because many therapeutic interventions are effective only if used correctly, which requires continuous personal investment of time and effort from patients. The epidemiological transition from acute diseases, where the emphasis was on cure, to chronic illnesses that instead require management also means that patients take on a lifetime burden. Poor 
adherence can lead to complications in professionalpatient relationships, additional ill health and expenditure for patients and their families, and the waste or misallocation of healthcare resources' (ref. 2, p.1). Given that it is the patient who decides on whether and how to take medications, we need to better understand over the counter $(\mathrm{OTC})^{3}$ and prescription use in chronic illness. ${ }^{4}{ }^{5}$ Qualitative research is designed to explore, interpret and gain a deeper understanding of social phenomena, and is well-suited to examine participants' experiences and use of medications. The shift in chronic illness care from passive patient to active partner coupled with policy support for shared decisionmaking and self-managing ${ }^{6-8}$ makes this topic particularly important. Our objective in this analysis was to understand medication use from the patient perspective and identify barriers to optimum care from onset of symptoms to early postdiagnosis. This information will be useful to healthcare providers who work with patients to improve adherence and who support shared decisionmaking. Our findings also highlight the potential pitfalls of unsupported self-management through a reliance on OTC medications, which may delay diagnosis and negatively impact outcome.

We used a qualitative approach ${ }^{9}$ to investigate people's early RA medication use in the context of their daily lives. In this paper, we focus on two predominant themes that emerged from the interviews: (1) the paradox of self-managing 'effectively' with OTC medication and (2) ambivalence and tensions around taking prescribed medication. We then discuss how medication use was a core self-management strategy for our participants, and how it influenced help-seeking, a timely diagnosis and effective treatment interventions. The accounts of people with early RA provided a rich source of qualitative data. The interviews offered insights into medication use, which may be transferable to others with similar illness experiences characterised by pain, unpredictable symptoms and concerns about the course of the illness and what to do about it. Other qualitative research shows that, like RA, various long-term conditions impact functional ability and daily life, and reveal how patient attempts to minimise incapacity provoke various decisions around medication use. ${ }^{5}$

As the goals of RA treatment are to ease pain, reduce inflammation and prevent joint damage, combinations of medications are required. Disease modifying antirheumatic drugs (DMARDS), biologics, non-steroidal antiinflammatory drugs (NSAIDS) and analgesics are treatments that include both OTC and prescribed medications. ${ }^{10}$ As well as combinations of medications, current evidence shows that DMARD therapy controls disease progression and improves long-term outcomes when initiated within the first 3 months of symptoms appearing. ${ }^{11}$ Delays in DMARD use are associated with poorer disease control and have been reported across communities and at several stages of disease from onset to securing specialist visits. A delay in DMARD use ranging from 6.5 to 11.5 months was reported in a Canadian study, which assumed that patients started the drug immediately upon prescription. ${ }^{12}$ A UK study concluded that for their participants "the majority of the delay in assessing patients with RA in secondary care lay at the level of the patient seeking medical advice" (ref. 13, p.3). Other qualitative research in the UK identified how multiple factors, for example, the nature of symptoms, knowledge of RA and attitudes towards healthcare providers, influenced when to consult in early RA patients. ${ }^{14}$ A study examining women's use of prescribed RA medications identified the decision-making process as complex and multifaceted. ${ }^{15}$ Further research investigating the experience of medication use in women and men with long-term multimorbidity (including RA) identified the central role of medication and patient ambivalence around taking different types of medicines. $^{5}$ We know little about the factors impacting decision-making and medication use in early RA from onset to diagnosis. Our study extends this knowledge by comparing OTC and prescribed medication use.

\section{PARTICIPANTS AND METHODS}

This analysis formed part of a wider study on the experience of help-seeking in early RA from onset of symptoms to early postdiagnosis. ${ }^{16}$ The overarching aim was to better understand the patient experience of early illness in the context of their daily lives and to identify delays along the care pathway. The original aim then was not to investigate medication use, but to understand the priorities and the experiences of the participants. Perhaps unsurprisingly, medication use emerged as an important theme. Other results have been published elsewhere. ${ }^{1617}$

\section{RECRUITIMENT}

A purposive sample was recruited through patient organisation websites, newsletters and information leaflets at local arthritis centres, as well as clinician offices. To be eligible, volunteers had to be adults with a self-reported RA diagnosis within the previous 12 months, and be able to converse in English (see table 1). Potential participants contacted the research coordinator either by phone or email; the study was described and volunteers were sent an informed consent document to be discussed and signed at the interview. All eligible participants who made contact agreed to participate and gave written consent. One person who agreed to participate died prior to the interview. Participants lived in a range of households in British Columbia (BC) and comprised individuals who were in paid employment, those receiving disability benefits, homemakers and retirees. The participants lived in communities ranging from Vancouver, a large city on the West coast, to small, mountain and rural communities in the north and east of BC. Participants were Caucasian, which does not reflect the diversity of parts of the Vancouver metropolitan area. All names are pseudonyms chosen by the participants. 


\begin{tabular}{|c|c|c|c|c|c|c|c|}
\hline & Age range & $\operatorname{Sex}(M / F)$ & Recruited via & $\begin{array}{l}\text { Symptom } \\
\text { onset to } \\
\text { seeing } R x\end{array}$ & $\begin{array}{l}\text { Seeking medical help for } \\
\text { symptoms leading to a } \\
\text { diagnosis/RA test }\end{array}$ & $\begin{array}{l}\text { Referral wait time to } \\
\text { see a rheumatologist }\end{array}$ & Diagnosis \\
\hline Alicia & $60 s$ & Female & Unknown & 1 year & 3 months & $6-8$ weeks & $\begin{array}{l}\text { Uncertain but treated for } \\
\text { RA }\end{array}$ \\
\hline Barbara Anne & $40 \mathrm{~s}$ & Female & $\begin{array}{l}\text { Family doctor's } \\
\text { office }\end{array}$ & 10 years & 1 year & 6 months & Diagnosed \\
\hline Bianca & $30 \mathrm{~s}$ & Female & $\begin{array}{l}\text { Rheumatologist } \\
\text { office }\end{array}$ & $\begin{array}{l}2 \text { years } \\
3 \text { months }\end{array}$ & 7 months & 2 months & Diagnosed \\
\hline Bonnie & $60 s$ & Female & $\begin{array}{l}\text { Arthritis } \\
\text { newsletter }\end{array}$ & 40 years & 20 years & No referral & Not diagnosed \\
\hline Charlize & $50 \mathrm{~s}$ & Female & $\begin{array}{l}\text { Arthritis } \\
\text { newsletter }\end{array}$ & 4 months & Less than 1 week & 3 months & Diagnosed \\
\hline Cynthia & $\begin{array}{l}\text { 60s } \\
\text { (estimated) }\end{array}$ & Female & $\begin{array}{l}\text { Arthritis } \\
\text { newsletter }\end{array}$ & 1 year & 5 months & 2 months & Diagnosed \\
\hline Danielle & $\begin{array}{l}40 s \\
\text { (estimated) }\end{array}$ & Female & $\begin{array}{l}\text { Rheumatologist } \\
\text { office }\end{array}$ & 8 years & 3 years & 2-3 months & $\begin{array}{l}\text { Uncertain but treated for } \\
\text { RA }\end{array}$ \\
\hline Debbie & $50 \mathrm{~s}$ & Female & $\begin{array}{l}\text { Rheumatologist } \\
\text { office }\end{array}$ & $\begin{array}{l}2 \text { years } \\
4 \text { months }\end{array}$ & 2 years 4 months & 3 months & Diagnosed \\
\hline Dodi & $\begin{array}{l}50 s \\
\text { (estimated) }\end{array}$ & Female & $\begin{array}{l}\text { Rheumatologist } \\
\text { office }\end{array}$ & 5-6 months & $2-3$ weeks & 10 months & Diagnosed \\
\hline Dorothy & $30 \mathrm{~s}$ & Female & $\begin{array}{l}\text { Rheumatologist } \\
\text { office }\end{array}$ & $\begin{array}{l}1 \text { year } \\
10 \text { months }\end{array}$ & 2 months & 2 months & Diagnosed \\
\hline Flossie & $50 s$ & Female & $\begin{array}{l}\text { Arthritis } \\
\text { newsletter }\end{array}$ & 24 years & 10 years & 6 weeks & Diagnosed \\
\hline Jackie & $40 \mathrm{~s}$ & Female & $\begin{array}{l}\text { Arthritis } \\
\text { newsletter }\end{array}$ & 8 months & 3 months & 9 months & $\begin{array}{l}\text { Uncertain but treated for } \\
\text { RA }\end{array}$ \\
\hline Jane & $60 s$ & Female & $\begin{array}{l}\text { Arthritis } \\
\text { newsletter }\end{array}$ & 8-9 months & 5 months & 1 month & Diagnosed \\
\hline Jane 2 & $50 \mathrm{~s}$ & Female & $\begin{array}{l}\text { Arthritis } \\
\text { newsletter }\end{array}$ & 4 months & 1 month & $6-8$ weeks & Diagnosed \\
\hline Jean & $50 \mathrm{~s}$ & Female & $\begin{array}{l}\text { Arthritis } \\
\text { newsletter }\end{array}$ & 19 years & 8 years & 2 months & Diagnosed \\
\hline Jessie & $50 \mathrm{~s}$ & Female & $\begin{array}{l}\text { Rheumatologist } \\
\text { office }\end{array}$ & 3-4 months & 3-4 weeks & 6 weeks & Diagnosed \\
\hline Julie & $50 \mathrm{~s}$ & Female & $\begin{array}{l}\text { Physiotherapist } \\
\text { office }\end{array}$ & 3 months & 3-4 weeks & 1 month & Diagnosed \\
\hline June & $50 s$ & Female & $\begin{array}{l}\text { Arthritis } \\
\text { newsletter }\end{array}$ & 3 months & unknown & 6 weeks & Diagnosed \\
\hline Kerry & $30 s$ & Female & $\begin{array}{l}\text { Arthritis } \\
\text { newsletter }\end{array}$ & 3 months & No delay & 10 days & Diagnosed \\
\hline
\end{tabular}




\begin{tabular}{|c|c|c|c|c|c|c|c|}
\hline & Age range & $\operatorname{Sex}(M / F)$ & Recruited via & $\begin{array}{l}\text { Symptom } \\
\text { onset to } \\
\text { seeing } \mathbf{R x}\end{array}$ & $\begin{array}{l}\text { Seeking medical help for } \\
\text { symptoms leading to a } \\
\text { diagnosis/RA test }\end{array}$ & $\begin{array}{l}\text { Referral wait time to } \\
\text { see a rheumatologist }\end{array}$ & Diagnosis \\
\hline Lee & $40 s$ & Female & $\begin{array}{l}\text { Family doctor } \\
\text { office }\end{array}$ & 14 years & Unknown & Unknown & $\begin{array}{l}\text { No diagnosis (has complex } \\
\text { multimorbidities tests } \\
\text { ongoing) }\end{array}$ \\
\hline Laurie & $60 s$ & Female & $\begin{array}{l}\text { Arthritis } \\
\text { newsletter }\end{array}$ & $1-2$ years & $1-2$ years & $\begin{array}{l}\text { At regular } \\
\text { rheumatologist regular } \\
\text { appointment }\end{array}$ & Diagnosed \\
\hline Maple & $40 s$ & Female & $\begin{array}{l}\text { Arthritis } \\
\text { newsletter }\end{array}$ & 2 months & 6-7 weeks & 1 day & Diagnosed \\
\hline Marie & $60 s$ & Female & $\begin{array}{l}\text { Rheumatologist } \\
\text { office }\end{array}$ & 3 weeks & 2 weeks & 1 week & Diagnosed \\
\hline Marlain & $50 s$ & Female & $\begin{array}{l}\text { Rheumatologist } \\
\text { office }\end{array}$ & $4-5$ years & $2-3$ years & $<6$ months & Diagnosed \\
\hline Martha & $70 \mathrm{~s}$ & Female & Unknown & 9 years & $6-8$ years & 1 year & Diagnosed \\
\hline Nicole & $30 \mathrm{~s}$ & Female & $\begin{array}{l}\text { Arthritis } \\
\text { newsletter }\end{array}$ & 1 month & 2 weeks & 2 weeks & Diagnosed \\
\hline Nicolette & $50 s$ & Female & $\begin{array}{l}\text { Rheumatologist } \\
\text { office }\end{array}$ & 12 months & 11 months & 1 month & Diagnosed \\
\hline Nora & $50 s$ & Female & $\begin{array}{l}\text { Rheumatologist } \\
\text { office }\end{array}$ & 11 months & 1 month & 3 months & Diagnosed \\
\hline Rain & $50 \mathrm{~s}$ & Male & Arthritis website & 4 years & 11 months & 10 months & Diagnosed \\
\hline Rosie & $60 s$ & Female & $\begin{array}{l}\text { Arthritis } \\
\text { newsletter }\end{array}$ & 26 years & 26 years & 1 month & Diagnosed \\
\hline Sally & $50 s$ & Female & $\begin{array}{l}\text { Arthritis } \\
\text { newsletter }\end{array}$ & 1 year & 2 months & 1 month & Diagnosed \\
\hline Sarah & $50 \mathrm{~s}$ & Female & $\begin{array}{l}\text { Arthritis } \\
\text { newsletter }\end{array}$ & 3 years & 16 months & 1 month & Diagnosed \\
\hline Shari & $60 s$ & Female & Unknown & 6 months & unknown & $\begin{array}{l}\text { No referral family } \\
\text { doctor diagnosis }\end{array}$ & Diagnosed \\
\hline Sharon & $60 s$ & Female & $\begin{array}{l}\text { Family doctor } \\
\text { office }\end{array}$ & 7 years & 2 years & 2 months & Diagnosed \\
\hline Sherry & $40 \mathrm{~s}$ & Female & $\begin{array}{l}\text { Rheumatologist } \\
\text { office }\end{array}$ & $9-10$ years & 5 years & 6 months & Diagnosed \\
\hline Smokie Jean & $60 s$ & Female & Rheumatologist & 40 years & 4 years & 3 weeks & Diagnosed \\
\hline Teresa & $50 s$ & Female & Unknown & 11 months & 9 months & 5 months & Diagnosed \\
\hline Yoda & $50 s$ & Female & $\begin{array}{l}\text { Rheumatologist } \\
\text { office }\end{array}$ & $\begin{array}{l}3 \text { years } \\
6 \text { months }\end{array}$ & $1-2$ weeks & 6 months & Diagnosed \\
\hline
\end{tabular}

${ }^{*}$ Age estimated by the interviewer when not given by the participant.

RA, rheumatoid arthritis. 
The University of British Columbia's Behavioral Research Ethics Board granted ethical approval for the study and all participants gave written informed consent.

\section{INTERVIEWS}

A topic guide was used to elicit in-depth accounts of participant experiences ${ }^{18}$ conducted at a time and place convenient to the participants (30 in their home and eight in a research centre). The topic guide was organised around three separate but overlapping sections: (1) symptoms/onset/impact including illness actions; (2) consulting the general practitioner (GP) and gaining a diagnosis/healthcare system and professionals and (3) postdiagnosis experiences. Open questions were asked, and probes and prompts used for elaboration. The guide was formulated after discussion with the multidisciplinary team including consumers (individuals with inflammatory arthritis) and rheumatologists. The topic guide was tested in a pilot study (eight participants) and the main format was unchanged. $^{19}$ A follow-up telephone interview allowed for further elaboration and clarification, and helped to check the main results of the initial interview (18 phone and one email follow-up were conducted). Interviews were conducted by AT, a research associate $(n=19)$, PA, an outreach coordinator at an arthritis clinic $(n=5)$ and LL $(n=1)$. The remaining interviews were conducted by a research coordinator $(\mathrm{n}=8)$ and three students supervised by PA $(n=5)$. AT and PA are both experienced qualitative researchers. Prior to data collection, AT conducted a field-work/interviewing training session. Field notes were taken to aid interpretation and validity of the data driven claims. Most interviews lasted between 60 and $90 \mathrm{~min}$. Two participans were interviewed with the spouse present.

\section{DATA ANALYSIS}

The audio-recorded interviews were transcribed verbatim. Transcripts were checked for accuracy against the recordings and the identifying information removed. Analysis was iterative and thematic, guided by a constant comparative approach. ${ }^{20}$ We used paper-based methods in the initial stages, and nVivo 7 was then used for storage and handling the extensive dataset. No preselected codes were identified prior to data analysis. AT and PA annotated a selection of transcripts independently and devised preliminary codes for all data. All authors read a selection of transcripts and, after discussion and negotiation, preliminary codes were revised, agreed upon and major themes identified. AT and PA then applied the codes to further transcripts and constantly compared the themes. Early broad themes related to medication use were clear, for example, taking OTC medicines as a major self-management strategy. Other themes emerged as analysis progressed, such as OTC medicine use as a paradox (the more 'effectively' people self-managed with OTC medication, the less likely they were to seek medical help, gain a diagnosis and be prescribed RA treatments). All transcripts were re-read as higher themes emerged. Deviant cases were sought and analyses and interpretations were discussed with a medical sociologist experienced in qualitative research as a form of peer-checking. The multidisciplinary author team also offered differing perspectives to aid the validity of the data driven claims. Statements made by participants are indicated by italics.

\section{RESULTS}

Both OTC and prescribed medication were core to illness management from onset to postdiagnosis. All participants experienced trial and error with a combination of drug regimens over time to gain efficacious treatment with minimum negative effects. All took a mix of medications, and most reported side effects and adverse reactions to varying degrees, depending on medicines for symptom relief and to maintain function in daily life. Most conveyed medication as highly effective in easing severe and debilitating symptoms and limiting the impact of the disease. Only a few reported medication use as unproblematic. The majority described concerns and anxieties about aggressive treatments and the risk of complications, which required monitoring and repeated medical appointments. Perhaps unsurprisingly, participants relayed ambivalence around medication use, grateful for the significant benefits while voicing concerns about the actual or potential harms such as the side effects (eg, mood changing, extreme fatigue and diarrhoea) or adverse effects that required long-term monitoring (eg, for liver or eye damage). Paradoxically, the more 'effectively' participants used OTC medications, the more likely was a delayed diagnosis and prescribed treatment, key to optimum disease outcome. Below we discuss two predominant themes from the interviews.

\section{Paradox: prediagnosis use of OTC medicines}

OTC medicines were conveyed as core to daily life and central to managing symptoms at onset of RA, for reported time periods that ranged from a few days to several years. Typically, participants described using OTC medicines for several weeks alongside other strategies, for example, pacing activities and turning to alternative therapists and treatments. Several participants expressed adapting to or pushing through the pain. Their priority to keep going swamped any general aversion to medication, or concerns about consuming large quantities of OTC analgesics, both routinely and for long periods.

Prior to diagnosis, participants relied on OTC medications for extended periods of time (see box 1, Alicia), using OTC analgesics to alleviate symptoms of pain, maintain function and facilitate normal life. For example, OTC medications enabled people to fulfil social roles and obligations, such as, in the family (see box 1, Flossie) and paid work (see box 1, Julie). Although participants were recruited within 12 months of diagnosis, many described taking OTC medicines for months/ 
Box 1 Paradox: prediagnosis use of over the counter medicines to function

I was just taking regular Tylenol and I mean I was sucking those back because I mean the pain was excruciating (Alicia).

When you have two little kids you just keep going...I kept going to skating lessons...the pain of tying up those laces... undoing them...getting them in and out of car seats...I didn't pay a lot of attention to it because I just thought...that's life...you just keep going and you take Tylenol or Advil and that's the way it is...I was almost full-time work and I really loved my work...I was so stimulated... really enjoyed my kids...I just kept taking pain medication to function (Flossie).

My husband had to help me to get a T-shirt on because everything was so stiff. I couldn't move and it was very painful...all these Tylenol / I would take up to 4 tablets of $650 \mathrm{mgs}$...by 11:00 the pain would go down to the point where I felt like I was happy to be at work. I could function fairly good. But the morning was a really tough time...At that point I had only taken occasionally more than six tablets a day to keep on going to work...it would go up to over 4,000 mgs. a day (Julie).

Just took Tylenol and Ibuprofen and tried to keep it at bay...to try...to see a doctor....wasn't worth it with the hassle of...baby and work. It wasn't that urgent...I spent...up to 14 hours a day on my laptop...eating Ibuprofen like a box of Smarties to try to keep the pain under control (Danielle).

I could hardly do anything....and when I started missing work I knew that that wasn't right...I tried the normal you know Tylenol or Aspirin or whatever to try and help as far as the pain went and nothing really worked. Nothing helped. So that's-again I decided -OK I can't go on like this on my own obviously. So again I decided -I made it clear that I had to go to the doctor and see what was wrong (Nicole).

years prior to their reported diagnosis of RA. One participant described negotiating symptoms and multiple roles (as a mother, student and employee) noting that, over a period of a few years, she was relying on ibuprofen (see box 1, Danielle). OTC analgesics were an integral component of daily life, allowing participants to keep busy and push through symptoms. Consequently, negotiating symptoms around daily life by relying on OTC medications meant delaying a GP consultation while they continued to self-manage. Significantly, in the context of busy lives, consulting the GP did not occur to some if they could carry on. For many, it was only when the OTC medicines failed to control pain and people could no longer function in core roles that they consulted their family doctor (see box 1 , Nicole).

\section{Self-assessing symptoms and regulating OTC medication intake}

Participants continued to self-regulate with OTC medicines after seeing their family doctors and prior to a diagnosis. This could mean changing medications or varying the dose, balancing symptom relief against side effects or doing a self-assessment check to gauge how many OTC medications would be required (see box 2, Bonnie). Danielle favoured OTC analgesics to those her
Box 2 Self-assessing symptoms and regulating OTC medicine intake

Every morning, I take Tylenol for arthritis. Some days, I take two every morning. Some times I take a lot more...I also take two at dinnertime. So a minimum of 4 a day. Sometimes more... Each day I ask myself: Now do I need them today? (Bonnie).

I didn't like the effects of the other stronger stuff that was prescribed at the doctor's because...I didn't have time for drowsiness in the program and then raising a child, drowsiness was just not in the equation so I just went back to the Ibuprofen...Being drowsy does not help you fight the fatigue (Danielle).

Interviewer: Where there any other things that you were doing besides the ice to manage it at that early point?

There were things I probably shouldn't have been doing but because...I already was on some inflammatory medications...I sort of upped the dose, not the dosage of the prescription medication but I would use 'over-the-counter' anti-inflammatories as well and by that I mean I would take extra doses of Aspirin.... with codeine and caffeine, which would get me through some of the times (Charlize).

[I kept going to the doctor] because they (pains) were getting worse and because I was taking Tylenol and you know Tylenol 3 and everything and it wasn't helping (Martha)

I am not one to take pills. I hate even taking Tylenol for a headache (Marlain)

I am just afraid to take medication. I don't even have Tylenol in the house. I take maybe, I don't know, through my whole life I might have taken three Tylenols or something (Nora).

GP had prescribed, to which she attributed significant side effects (see box 2, Danielle). Another participant took OTC medications together with anti-inflammatory medications prescribed for another condition (see box 2, Charlize). Martha relied on both OTC and prescription painkillers over a period of years when she made several visits to her doctor with escalating symptoms of pain (see box 2, Martha). The quotes in this second section illustrate how people self-managed their symptoms in daily life by self-regulating OTC medications: doing a self-assessment check to gauge how many OTC meds would be required (Bonnie), increasing OTC medications when required (Charlize), choosing to take OTC medications to avoid side effects (drowsiness) from prescription drugs (Danielle). Although the majority relied on OTC medicines to control symptoms and function in daily life, a small minority of participants explicitly noted a clear aversion to OTC medicines (see box 2, Marlain, Nora). Self-regulating OTC medications was a core self-management strategy, which for many meant avoiding a GP consultation. This 'effective' selfmanagement hampered a speedy diagnosis and prescribed treatments that could reduce disease damage.

\section{Ambivalence: postdiagnosis prescribed medication use}

In the face of debilitating, severe and unpredictable symptoms and uncertainties about disease prognosis, 
participants were relieved to see a specialist and to be prescribed medications designed to control disease activity and improve symptoms. An RA diagnosis, however, was treated with ambivalence. First, participants described relief at being diagnosed but concern about having to live with a long-term condition. Second, participants came to rely on multiple prescription medications, but voiced a desire to come off/reduce them due to experiencing side effects and concerns about the potential toxicity and adverse effects.

Most participants were familiar with analgesics and anti-inflammatory drugs (both OTC and GP prescribed) and had been taking them to relieve symptoms and function in daily life, prior to RA diagnosis (see boxes 1 and 2). Prescribed medications were perceived differently. Participants reported that they were faced with aggressive treatment (Ruth) and drug cocktails (Jane-2), for which they were grateful but also had misgivings about. Ambivalence was expressed most clearly around taking DMARDS. For example, although desiring treatment, some participants delayed initiating or filling prescriptions. A few delayed taking DMARDS because they anticipated disruption at work or on holidays (see box 3, Cynthia). One participant described a combination of reasons, which put her off methotrexate: a lack of

Box 3 Ambivalence: a need for and an aversion to prescribed medications

The truth is...that right after my (specialist) appointment (Husband) and I were planning to go to Edmonton and I didn't want to be starting on a new medication (DMARD) when I was on a trip...I waited to see my GP (Cynthia).

Since he didn't give me a lot of information, the specialist, about Methotrexate I had to do a lot of reading on my own about it and I was very reluctant, to use it...So it was probably a month after I was prescribed it to when I actually started taking it... It was...injectible...it's a little bit more of a hassle to take... when the drugs are so strong you'd like to know a little bit more information than if it was...take an antibiotic and you're going to feel better. It's...take this drug and maybe in six months you'll feel better...Well Methotrexate was also used to treat cancer so it's a very, very strong drug...(Bianca)

We talked a little bit about...treatment and things that might help and he (rheumatologist) asked me how I felt about medications... because I struggle with other health issues and I take so many different medications already I asked if we might be able just to try managing things on our own (GP and me) before we got into a big treatment sort of plan and he said that was fine. He did prescribe a pain killer that was a little bit more than what my family physician had given me and he said:..."See how you do and if you need to come back before, call me but otherwise we'll see you in two months."... but things didn't get a lot better and I still missed the odd day of work...So when I went back to the (rheumatologist) I said...I need help...So then we started talking about treatment options...He put me on a treatment program (DMARDS)...the medication has been a good thing because I tried to go without it and I couldn't (Nicole). information from her rheumatologist; having to inject it and recognising that it was a cancer treatment all meant that Bianca delayed taking methotrexate until she could discuss it with her family doctor (see box 3, Bianca). Another participant was reluctant to take prescribed DMARDS because she initially wanted to manage the RA herself along with her other chronic conditions and limit her multiple medication intake (see box 3 , Nicole).

Nearly all of the participants described side effects. Most participants sought optimum symptom relief, disease control and minimum side effects, which meant finding a combination of prescription medications which suited them. For many, this was a process of trial and error, as the side effects were sometimes extreme and outweighed the benefits (see box 4, Flossie). Several noted that they continued to take, but were keen to reduce the level/frequency of their medications because of their aversion to them (see box 4, Debbie). Yet only one person noted that she had stopped taking all prescription medications, and this was reportedly with the knowledge of her family doctor and rheumatologist (see box 4, Sharon).

Box 4 Ambivalence: weighing up the benefits and potential harms of prescribed medications

The Methotrexate cleared all the symptoms of rheumatoid...right away. Like eventually, it was just the side effects I couldn't tolerate...It created a whole host of other symptoms that were not weighing up the benefits...it....alters your psyche...it's harder to dig your happy self out of that (Flossie).

After my first shot (a biologic) I was able to get off the chair without any help...by the third shot I think I was almost back to normal...I am going to ask Dr. X. if I can take my [biologic] If I can not do it once a week maybe every 10 days. Just slowly and see how my body reacts to that. Because when I get my shot the first two days now I don't feel that well. I'm feeling a little bit agitated (Debbie).

The Methotrexate and Sulfasalazine so changed my personality. I was miserable. When I think back on the nine months it's like a blur. It's like something I don't really want to remember. I just quit the medication and then I went back to see [the rheumatologist] and he said: "Well you had a reaction". And he kept pooh, poohing me off... He's very dedicated. But he just needs to crawl into his patients' shoes sometimes (Sharon).

I have been on Methotrexate for just over a month. And it seems to be working ...But it terrifies me (Sherry).

I just have to take it. I don't think my attitude has changed. If I have to I have to...It will still be hard to do because I know I am destroying other parts of my body with the medications...। wouldn't take it if I didn't have to (Nora).

So either way you're treated there is a negative side effect... you try not to kill yourself with the treatment and still manage your daily life (Charlize)

I would like to get off the Prednisone as soon as possible...it's almost weird....Prednisone is a magic drug until you find out the side effects...It's almost cruel to give it to people because it works so well (Jessie). 
A few did not report side effects and they were prepared to endure potential adverse effects to their system, if it meant that they could function (see box 4, Sherry). Nora noted how she tolerated an aversion to DMARDS but had a need for them (see box 4, Nora). In this example, an antimedication attitude combined with knowledge of the potential toxicity of DMARDS is outweighed by the benefits (of symptom relief and functional ability) gained.

The tensions underpinning aggressive treatment as care (as described by participants) were clear in the accounts. Participants balanced the risks (of toxicity and adverse effects) and benefits (effective treatment of disease) of the prescribed RA medications (see box 4, Charlize). Another contradiction voiced by many was the use of prednisone, a drug that offered relief but also side effects and could only be taken for limited periods of time (see box 4, Jessie). Overall, ambivalence around taking effective and intensive treatments was amplified by information gathered from multiple sources (eg, the Internet and family members' experiences) combined with a reported lack of opportunity to meaningfully discuss risks, benefits and options in the specialist consultation.

\section{DISCUSSION}

Paradox and ambivalence arose around medicine use in the accounts of study participants, recently diagnosed with RA. Participants commonly reported OTC medication use as an 'effective' self-management strategy prior to seeking medical attention, which for many participants ultimately delayed diagnosis and effective treatment. Paradoxically, the more 'successful' self-managers risked longer delays and more harmful outcomes. Postdiagnosis, although most participants conveyed a strong desire for prescription medicines, they also described an aversion to them and concerns with complications of both side effects and adverse effects. Understanding patient perceptions and priorities can inform several elements of practice and care, fostering effective patient-provider communication and shared decision-making. Ultimately, this may lead to more prompt diagnosis and higher levels of adherence.

Our study has limitations. Given the nature of qualitative research, we do not claim to make generalisations from this sample, although it is an in-depth analysis of a relatively large dataset. The participants recruited could have been more inclined than others to be active selfmanagers or help-seekers. ${ }^{21}$ They could also have been more prone to have problems, complex trajectories and experience tensions around help-seeking and medicine use than others with RA. Despite the purposive approaches, we interviewed just one man and all participants were Caucasian, so the sample is limited. Trainee/ multiple interviewers may have affected the quality in a minority of the interviews, though this was taken into account in the analysis. Nevertheless, the in-depth analysis gave insight into how medication use was experienced over time, taking account of the changing context in which people manage RA from symptom onset to diagnosis. It is possible that people with other chronic conditions may have similar experiences. For example, there are similarities between RA and multiple sclerosis (MS). Both are chronic, systemic, autoimmune conditions with fluctuating pain and fatigue disrupting life roles. ${ }^{16}$ Given that symptoms and activity disruption drove some of the prediagnosis medication decisions in the present study, there may be questions to explore in MS and other similar conditions.

Consistent with the literature spanning 50 years, ${ }^{22} 23$ participants commonly reported delaying a GP consultation. A significant finding was that it simply did not occur to people to consult their GP or other health professional, as long as OTC medicines masked symptoms for prolonged periods. The delays some participants reported in obtaining prescribed medication reflected the experiences of patients with chronic illness in a study 40 years ago. ${ }^{24}$ More recent research has revealed how people's use of OTC medications to manage early RA symptoms contributes to delays in seeking a medical appointment. ${ }^{12}$ This may point to a need to increase public awareness about the symptoms of inflammatory types of arthritis and the importance of early intervention for optimal outcomes. The attitude towards managing symptoms oneself and the prolonged use of OTC medicines could be unintentionally encouraged by policy messages about the inappropriate use of overburdened health systems and the need for selfmanagement. ${ }^{3} 8$ The accounts revealed a reluctance to go on prescribed medicines, and a desire to reduce or come off them to avoid side effects. Another significant finding was that although participants were concerned about the risks of prescription medicines, consistent with other populations, ${ }^{25}$ they largely reported little concern about using OTC medications because they perceived them as less harmful compared with the recommended prescription medicines. This mirrors what others have identified in terms of encouraging a more active and empowered patient, which may increase OTC medicine use and underplay the harms involved. ${ }^{38}$ The findings also show that patients assess risk when making decisions about medication use in ways that may not be consistent with advice from health professionals.

Consequently, these findings have implications for policy and practice. First, the ambivalence that was conveyed by so many of the participants supports the need for concordance, which involves clinician and patient discussion around the patient concerns, experiences, perspectives, ${ }^{5}{ }^{19}$ risks and benefits associated with both prescribed medications ${ }^{26}$ and OTC medicines. In this way, interventions are needed that incorporate patient perspectives ${ }^{26}$ and priorities in meaningful ways. Second, medications occupy a central place in people's lives as they self-manage prior to seeking formal help. The longestablished concept of the 'iceberg of illness' ${ }^{27}$ bears 
witness to this extensive activity long before policy extolled the version of an expert patient who is to be encouraged to self-manage. ${ }^{7}$ People do not take OTC medications in a cultural vacuum. Established cultural attitudes of stoicism, more recent notions of overburdened health systems and taking responsibility for one's health combine to encourage OTC medicine use and the avoidance of GP consultations. As such, it is perhaps unsurprising that people self-medicated for long periods of time and used maximum dosage drugs to help contain symptoms, even when the symptoms were persistent and severe. Third, a mix of potent drugs that work well but also have negative effects build on the cultural ambivalence and aversion to medications, which people often already have. ${ }^{5}$ The cocktail of drugs offered as aggressive treatment is complicated further by the existence of multimorbidity, associated poly-pharmacy and drug interactions or fears of such. These factors need to be considered as part of the patient experience of medication use, which informs decision-making.

\section{CONCLUSIONS}

Our research re-emphasises the role of and tensions around medication use in a changing healthcare environment. It suggests that one key challenge facing interventions to improve a timely RA diagnosis is to redress the public health message of appropriate help-seeking and the individuals' responsibility to self-manage. Unless mixed messages are clarified, people may well continue to use OTC medicines extensively and inappropriately to mask severe symptoms and maintain function in their daily lives. Interventions also need to acknowledge how the patient and clinician roles are changing, as well as recognise the complications of multimorbidity and how these separate but often interlinking factors impact adherence. Interventions need to better communicate the need to gain treatment and the ramifications of having a chronic, systemic disease. RA is more than just joint pain, which many people feel comfortable in selftreating rather than gaining a diagnosis. Finally, the risks and benefits of OTC medications compared with prescription medications, need to be clarified in ways that support more informed decision-making in RA.

\section{Author affiliations \\ ${ }^{1}$ Department of Occupational Science \& Occupational Therapy, University of British Columbia, Vancouver, British Columbia, Canada \\ ${ }^{2}$ The Arthritis Research Centre of Canada, Richmond, Nr Vancouver, British Columbia, Canada \\ ${ }^{3}$ Department of Rheumatology Liaison \& Outreach Services, Mary Pack Arthritis Program, Vancouver, British Columbia, Canada \\ ${ }^{4}$ Department of Physical Therapy, University of British Columbia, Vancouver, British Columbia, Canada}

Acknowledgements The Early Inflammatory Arthritis Help-Seeking Experience (ERAHSE) team includes all authors and the following members: Susan Cox, Monique Gignac, Alice Klinkhoff, Stanley Lubin and Shahin Walji. We also extend our thanks to consumer collaborators: Otto Kamensek, Colleen Maloney and Heather McArthur. We are grateful to the participants who shared their time and experiences. We also thank the Canadian Institutes of Health Research for funding this study. And also thanks to Zubin Amarsi, Cynthia McDonald, Katie Adam, Charlene Yousefi, Jasmine Rockwell and Jenny Leese who were students/research assistants on the project.

Contributor LL conceived the idea of the study. All authors made substantial contributions to the study design. AT and PA conducted the bulk of the interviews in the study; LL conducted one interview. AT and PA led the initial analysis of the data and $L L$ and $C B$ provided input into the data analysis. $L L$, $\mathrm{CB}, \mathrm{AT}$ and PA all contributed to the interpretation of the results. AT prepared the initial draft of the manuscript and circulated it to all authors repeatedly. All authors read and commented on the drafts, making critical revisions and intellectual contributions. All authors approved the final version to be published. LL was the PI. AT, PA and CB were the Cls of the study. All authors, external and internal, had full access to all of the data (including statistical reports and tables) in the study and can take responsibility for the integrity of the data and the accuracy of the data analysis.

Funding Funded by Canadian Institutes of Health Research \# 172323. The study sponsors had no role in the study design, data collection, analysis and interpretation, writing of the report and decisions to submit the article. Researchers are independent from funders.

Competing interests All authors have completed the Unified Competing Interest form at http://www.icmje.org/coi_disclosure.pdf (available on request from the corresponding author) and declare that (1) AT, PA, CB and LL have support from the University of British Columbia and Vancouver Coastal Health for the submitted work; (2) AT, PA, CB and LL have no relationships with the companies that might have an interest in the submitted work in the previous 3 years; (3) their spouses, partners or children have no financial relationships that may be relevant to the submitted work and (4) AT, PA, CB and LL have no non-financial interests that may be relevant to the submitted work.

Ethics approval University of British Columbia Behavioural Research Ethics Board.

Provenance and peer review Not commissioned; externally peer reviewed.

Data sharing statement Further data are available relating to quotes around OTC and prescription medication use. Please contact Linda Li for access at Ili@arthritisresearch.ca.

\section{REFERENCES}

1. Kelly C, Hamilton J. What kills patients with rheumatoid arthritis? Rheumatology 2007;46:183-4.

2. May $\mathrm{C}$, Montori $\mathrm{V}$, Mair F. We need minimally disruptive medicine. BMJ 2009;339:485-7.

3. Kennedy JG. Over the counter drugs. BMJ 1996;312:593-4.

4. Hughes C. Monitoring self-medication. Expert Opin Drug Saf 2003;2:1-5.

5. Townsend A, Hunt K, Wyke S. Managing multiple morbidity in mid-life a qualitative study of attitudes to drug use. BMJ 2003;327:837.

6. Weiss $\mathrm{M}$, Britten $\mathrm{N}$. What is concordance? Pharm $J$ 2003;271:493-5.

7. Department of Health. The expert patient: a new approach to chronic disease management for the 21st century. London, UK; 2000, Report.

8. Blenkinsopp A, Bradley C. Over the counter drugs: patients, society, and the increase in self medication. BMJ 1996;312:629-32.

9. Barbour RS. The role of qualitative research in broadening the 'evidence base' for clinical practice. J Eval Clin Pract 2000;6:155-63.

10. Fleischmann R. Safety and efficacy of disease-modifying antirheumatic agents in rheumatoid arthritis and juvenile rheumatoid arthritis. Expert Opin Drug Saf 2003;2:347-65.

11. Li L, Badley E, Mackay C, et al. An evidence-informed, integrated framework for rheumatoid arthritis care. Arthritis Rheum 2008;59:1171-83.

12. Tavares R, Pope J, Tremblay J, et al. Early results from the understanding near-term care of very early rheumatoid arthritis (uncover) multi-centre, retrospective, cohort: lag-times to early rheumatoid arthritis care with disease modifying anti-rheumatic drugs. Arthritis Rheum 2006;54:S415.

13. Kumar K, Daily E, Carruthers D, et al. Delay in presentation to primary care physicians is the main reason why patients with 
rheumatoid arthritis are seen late by rheumatologists. Rheumatology 2007;46:1438-40.

14. Sheppard J, Kumar K, Buckley C, et al. 'I just thought it was normal aches and pains': a qualitative study of decision-making processes in patients with early rheumatoid arthritis. Rheumatology 2008;47:1577-182.

15. Salt E, Peden A. The complexity of the treatment: the decision-making process among women with rheumatoid arthritis. Qual Health Res 2011;21:214-23.

16. McDonald H, Dietrich T, Townsend A, et al. Exploring occupational disruption after the onset of rheumatoid arthritis. Arthritis Care Res 2012;64:197-205.

17. Townsend A, Cox S, Li LC. Qualitative research ethics: enhancing evidence-based practice in physical therapy. Phys Ther 2010;90:615-28

18. Britten N. Qualitative research and the take-up of evidence-based practice. J Res Nurs 2010;15:537-44.

19. Townsend A, Adam P, Cox S, et al. Everyday ethics and help-seeking in accounts of early rheumatoid arthritis. Chronic IIIn 2010;6:171-82.

20. Thorne S. Data analysis in qualitative research. Evid Based Nurs Notebook 2000;3:68-70.
21. Townsend A, Amarsi Z, Backman C, et al. Communications between volunteers and health researchers during recruitment and informed consent: qualitative content analysis of email interactions. J Med Internet Res 2011:13:e84.

22. Koos E. The health of Regionville; what the people thought and did about it. 2nd edn. New York: Hafner, 1954.

23. Stack R, Shaw K, Mallen C, et al. Delays in help seeking at the onset of the symptoms of rheumatoid arthritis: a systematic synthesis of qualitative literature. Ann Rheum Dis 2011; 71:493-7.

24. Dunnell K, Cartwright A. Medicine takers, prescribers and hoarders. London: Routledge \& Kegan Paul, 1972.

25. Kumar K, Gordon C, Toescu V, et al. Beliefs about medicines in patients with RA and SLE: a comparison between patients of South Asian and White British origin. Rheumatology 2008;47:690-7.

26. Van den Bemt BJF, Zwikker HE, Van den ende CHE. Medication adherence in patients with rheumatoid arthritis: a critical appraisal of the existing literature. Expert Rev Clin Immunol 2012;8:337-51.

27. Kooiker S. Exploring the iceberg of morbidity; a comparison of different survey methods for assessing the occurrence of everyday illness. Soc Sci Med 1995;41:317-32. 